BMJ Open Sport \& Exercise Medicine

\title{
Video games and their associations with physical health: a scoping review
}

\author{
Vincent Huard Pelletier, ${ }^{1}$ Arianne Lessard, ${ }^{2}$ Florence Piché, ${ }^{2}$ Charles Tétreau, ${ }^{2}$ \\ Martin Descarreaux (D) ${ }^{2}$
}

To cite: Huard Pelletier V, Lessard A, Piché F, et al. Video games and their associations with physical health: a scoping review. BMJ Open Sport \& Exercise Medicine 2020;0: e000832. doi:10.1136/ bmjsem-2020-000832

- Supplemental material is published online only. To view please visit the journal online (http://dx.doi.org/10.1136/ bmjsem-2020-000832).

Accepted 13 September 2020

Check for updates

(c) Author(s) (or their employer(s)) 2020. Re-use permitted under CC BY-NC. No commercial re-use. See rights and permissions. Published by BMJ.

${ }^{1}$ Department of Anatomy, Universite du Quebec a TroisRivieres, Trois-Rivières, Canada ${ }^{2}$ Department of Human Kinetics, Universite du Quebec a TroisRivieres, Trois-Rivières, Canada

\section{Correspondence to} Martin Descarreaux; martin.Descarreaux@uqtr.ca

\section{ABSTRACT}

Objective The objective of this scoping review is to investigate the possible links between the practice of video games and physical health. It seeks to answer the following question: What are the physical health consequences of playing video games in healthy video game player? and How is it currently investigated?.

Methods A scoping review was conducted to identify observational and experimental studies pertaining to our research question. Retrieved papers were screened using a two-phase method first involving a selection based on titles and abstracts. Then, potentially relevant studies were read and triaged. The final set of included studies was analysed, and data were subsequently extracted.

Observational studies and experimental studies were assessed using the appropriate Cochrane Risk of Bias Tool and data were synthetised according to specific physical health and related health behaviours.

Results Twelve peer-reviewed articles were retained for further analyses. Results of this scoping review suggest preliminary evidence that time spent gaming is associated with some health outcomes indicators. Our results indicate preliminary evidence that increased gaming time is associated with higher body mass index and lower self-reported general health status. There is insufficient evidence to conclude on a possible association between gaming time and physical activity or sedentary behaviours, sleep or fatigue, musculoskeletal pain or dietary behaviours.

Conclusion The results of this sopping review suggest an association between increased video game playing time and a deterioration in some physical health indicators but available evidence is scarce, precluding from any strong conclusion.

\section{INTRODUCTION}

The first-ever publicly released video game was introduced in 1958; it was called Pong and it was a very rudimentary representation of a tennis game. Since then, the video game industry has continued to expand and diversify, gradually moving from arcades to consoles until the arrival of the internet in the mid-1990s. Video gaming is now part of the daily lives of more than $75 \%$ of North American households, ${ }^{1}$ and revenues of the video game industry now outpace those of the film and online streaming industry. ${ }^{1}$
Several types of games are available to meet the needs and desires of a large number of consumers, which explains why there are players in each age group and in both sexes. ${ }^{1}$ Over time, a professional scene has emerged and grown in popularity, to the point where electronic sports (eSports), which are defined as video gaming in a competitive environment or settings, ${ }^{2}$ now offer salaries comparable to traditional sports and could be included in the 2024 summer Olympic Games. ${ }^{3}$ Such rapid development has led educational institutions to implement eSports development programmes that can also provide scholarships to promising students. In the United States, at least 50 colleges have varsity eSport teams under the National Association of Collegiate eSports, and more than 20 offer scholarships to their athletes. ${ }^{4}$

Although video gaming and eSport has seen a tremendous growth in popularity in the past decades, studies suggest that these activities may have several negative impacts on psychological and physical health. ${ }^{5}$ First, playing violent video games is seen as a desensitising factor to violence in the real world and has been linked to several tragic events such as the Columbine and Sandy Hook massacres by the media and public figures. ${ }^{6}$ This relationship, however, may not be causal and playing these types of games may not increase the chances of becoming violent for oneself. ${ }^{6}$ Another often-raised problem is that many video game enthusiasts seem to devote a large number of hours to gaming. For instance, in South Korea and Singapore, where video games are ubiquitous in popular culture, many young people are reported to play for more than 20 hours a week. ${ }^{7}$ Cultural differences may exist in other parts of the world, but gaming addiction was considered serious enough for the American Psychiatric Association to add video game addiction as a pathology in the Diagnostic and Statistical Manual of Mental Disorders (DSM-5). ${ }^{8}$ However, this addition raises questions, as some authors suggest that the 
pathology definition and the different behaviours characterising the diagnosis should be clarified. ${ }^{9}$

Psychological health is not the only concerning aspect surrounding video game players. Indeed, with the exception of active games, video games are most often played while sitting in front of a screen, using either a cell phone, tablets, a console attached to a television or a computer monitor. Screen time is a major concern for public health organisations, as it has several negative effects. In fact, people who report higher screen time are physically less active, more likely to be overweight ${ }^{10}$ and consume significantly more caffeine and calories. ${ }^{11}{ }^{12}$ In addition, sleep quality is often negatively related to screen time, ${ }^{13}$ as are some depressive symptoms. However, it remains to be determined if evidence regarding negative consequences can also be observed in video game players. In this study, video gamers are defined as individuals who play video games at least 1 hour per week. ${ }^{14}$ They certainly spend some time in front of a screen, but their sessions may be more interactive than passive television viewing. Furthermore, depending on the type of games played, the practice level and their social context, video game players can be classified in various categories. ${ }^{15}$ Thus, video gaming is a multi-faceted phenomenon that not only attracts different types of individuals, but that can also provide different types of experience depending on the context. ${ }^{16}$ Nowadays, there is no clear consensus with regard to the different physical health indicators and behaviours associated with video gaming played by healthy video games players, as very few studies focused on this topic.

Video games have become an important part of people's daily lives in a relatively short period of time, and scientific evidence focusing on the impact of gaming, whether it is organised or solitary, are progressively emerging and shedding light on significant public health issues. Given the rapidly growing popularity of gaming and organised eSports and the publicly growing concerns about video game effects on health, ${ }^{17}$ the following scoping review focuses on how video game playing impacts on the physical health indicators and behaviours of healthy players.

\section{MATERIALS AND METHODS}

A scoping review approach was chosen to undertake this literature review on the physical health of video game players. The scoping review was identified as the most appropriate format for this study, as: (1) the literature on this subject appears to be incomplete, and suggestions could be made to fill existing research gaps, (2) this format allows the extraction of results while taking into account the context of the studies and (3) the scoping review can be used to verify the relevance of conducting a complete systematic literature review. ${ }^{18}$ The following five methodological steps have been conducted and will be presented below: (1) identification of the research question, (2) identification of relevant studies, (3) selection of studies, (4) data extraction and (5) gathering, synthesis and presentation of the review's results.
According to the University's Human Research Ethics Committee policy, a scoping review does not require an IRB certification.

\section{Identifying the research question}

In order to address the main objective of the study, which is to increase the broad knowledge about the consequences of video gaming on physical health of healthy video game players, the following research question was developed: What are the consequences of playing video games on physical health indicators and behaviours in healthy video game players, and how is it currently investigated? Since the definition of physical health can be broad and may vary from one study to another, physical health was defined, for this study, as multi-component construct that refers to health complaints and acute health concerns (notably injuries), but also includes lifestyle choices like commitments to physical activity, nutritious diets and sufficient sleep. ${ }^{19}$

\section{Identification of relevant studies}

Nine databases (SPORTDiscuss, Academic Search Complete, CINAHL, Cochrane, MEDLINE, PsycINFO, Pubmed, ERIC, APA PsycNET) were searched for articles published between January 1990 and July 2019. For each databases, we used the following keywords: ('Video game' OR 'Computer game' OR 'Online game' AND 'fitness' OR 'musculoskeletal injury' OR 'lifestyle' OR 'physiological health' OR 'physical health').

\section{Studies selection}

To define the inclusion criteria for the articles to be included in this scoping review, the PICO framework was used. ${ }^{20}$ Articles that discussed the effect of video games in non-healthy videogame players (with a reported medical diagnosis), as well as articles focusing on active or exergames (like Wii Sports) or the effect of playing video games on violent behaviour were excluded. Finally, studies exploring outcomes not directly related to physical health as well as non peer-reviewed articles, case studies and reviews were excluded.

For each of the subsequent steps, two reviewers (FP \& VHP) were involved in the article selection. Whenever reviewers disagreed on the relevance of the articles, a third reviewer (MD) was involved to settle in favour of one or the other. First, articles whose title was clearly irrelevant to our research question were excluded. Abstracts from the remaining articles were then screened and irrelevant studies were further excluded using the same criteria. The last step involved thoroughly reading the remaining articles to select only those that convincingly met the inclusion criteria.

\section{Data extraction}

Data from the 11 selected studies were extracted using an Excel form where the following information was compiled (see online annexe 1): authors names and year of publication, main objectives of the study, physical health outcomes and main results. 


\section{Gathering, synthesis and presentation of results}

The content of the studies from the Excel form was discussed by the two reviewers (FP \& VHP) to highlight relevant information about the consequences of video games on various physical health indicators and behaviours. Studies such as literature reviews discussing physical health and video games that were not part of the final selection were used to compare results and discuss the state of the current evidence on the topic.

Assessment of risk of bias was conducted independently by two authors (AL \& MT), using the methodology recommended by Guyatt $e t$ al for observational studies. ${ }^{21}$ This tool assesses six potential sources of bias: selection bias (inappropriate sampling), performance bias (flawed measurement of exposure), detection bias (flawed measurement of outcome), attrition bias (incomplete follow-up, high loss to follow-up), selective reporting bias (selective, incomplete or absent outcome reporting) and all other sources of bias. All the included studies were assessed for quality. Each item was rated either high, low or unclear risk of bias. For experimental studies, the 'Revised Cochrane risk-of-bias tool for randomised trials' was used ${ }^{22}$ Grading of the evidence was conducted for each physical health outcomes and judgement of the strength of the available evidence included risk of bias analyses as well as strength and consistency of associations. ${ }^{23} 24$

\section{RESULTS}

\section{Descriptive statistics}

Of the 2356 papers gathered from the search strategy, 251 abstracts and titles (10.6\%) met our inclusion criteria. After the full-text reading stage of our scoping review, the list of articles was considerably shortened and included eleven peer-reviewed articles gathered by the search and one article suggested by an expert $(<1 \%)$ that were retained for further analyses (see figure 1). Of these 12 studies, $10(83 \%)$ had used a cross-sectional design,${ }^{25-33}$ one $(8 \%)$ had a longitudinal design ${ }^{34} 35$ and one $(8 \%)$ was an experimental randomised cross-over study. ${ }^{36}$ Five studies were published between 2005 and 2010, ${ }^{25} 303134$ while the remaining seven studies were published after 2010 (see table 1). ${ }^{26-29} 333536$ With regard to the participants that were investigated, every study included (100\%) adolescents, ${ }^{25-32}$ 34-36 while four (33\%) also included adult participants. ${ }^{27} 293033$ Concerning the participants' gender, nine studies (75\%) examined both men and women, ${ }^{25} 272830-35$ while two (16\%) only focused on men $^{29} 36$ and another study (8\%) did not specify the participants' gender. ${ }^{26}$ Finally, the different studies involved participants from various countries or regions of the world (see table 2), as six studies $(50 \%)$ were conducted in Europe, ${ }^{27-29} 32 \quad 33 \quad 36$ five (42\%) in North America $^{25} 26303435$ and one (8\%) in South America. ${ }^{31}$ Finally, seven studies $(58 \%)$ had a large number of participants (more than 500), ${ }^{25} 2728$ 30-33 two had an intermediate number of participants (100-499) ${ }^{34} 35$ and three had a low number of participants (less than 100). ${ }^{26} 2936$

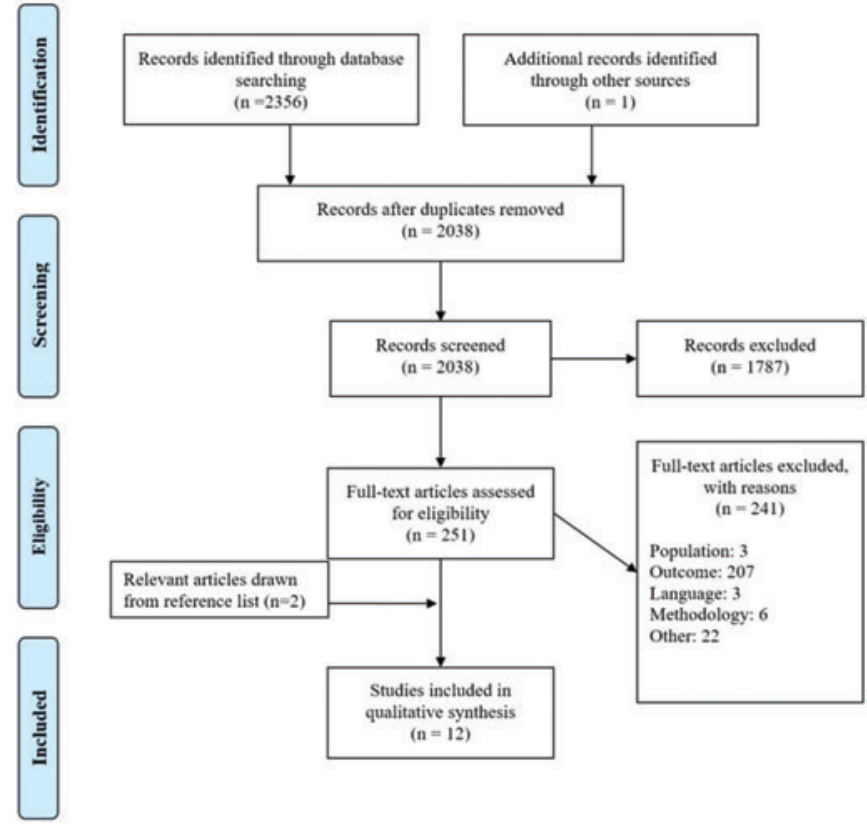

Figure 1 PRISMA flow chart.

\section{Risk of bias assessment}

The eleven observational studies ${ }^{25-35}$ and one experimental study ${ }^{36}$ were assessed for quality. All observational studies had issues regarding detection bias, mostly because homemade questionnaires or non-validated protocols were used to measure outcomes. Three studies ${ }^{252634}$ had a high risk of bias, either due to selection, missing data, reporting or measurement bias, such as voluntary participants and non-randomised samples, and incomplete reporting of some outcomes. Nine studies ${ }^{27-33} 3536$ presented a low risk of bias. Table 3 summarises the risk of bias assessment.

\section{Physical health indicators and behaviours}

Several key health-related variables were studied in the articles selected in this scoping review. Five studies (42\%) investigated sleep or fatigue, ${ }^{27} 2932-34$ four (33\%) examined body mass index (BMI), 2529303335 four (33\%) were interested in general health, ${ }^{30}{ }^{32-34}$ three (25\%) considered musculoskeletal pain, ${ }^{26} 2831$ three $(25 \%)$ investigated levels of physical activity ${ }^{26} 2933$ and three $(25 \%)$ measured energy intake/expenditure or nutrition. ${ }^{29} 3336$

\section{Assessment tools}

A vast majority $(83 \%)$ of the studies under examination used questionnaires to gather data. ${ }^{26-35}$ Of these studies, nine $(75 \%)$ chose to develop a homemade questionnaire, ${ }^{25} \quad 26 \quad 28 \quad 30-32 \quad 34 \quad 35$ while two (17\%) decided to use a pre-existing and validated questionnaire. ${ }^{27} 29$ Only one (8\%) study opted to measure a physical health outcome using objective measures. ${ }^{36}$ Chaput and colleagues ${ }^{36}$ used a direct measurement method to evaluate energy intake and 
Table 1 Study designs

\begin{tabular}{|c|c|c|c|}
\hline \multirow[b]{2}{*}{ Authors } & \multicolumn{3}{|l|}{ Study design } \\
\hline & Cross-sectional & Longitudinal & Experimental randomised study \\
\hline Chaput et al $2011^{36}$ & & & $x$ \\
\hline Desai et al $2010^{25}$ & $\mathrm{x}$ & & \\
\hline DiFrancisco-Donoghue et al $2019^{26}$ & $x$ & & \\
\hline Exelmans et al $2015^{27}$ & $x$ & & \\
\hline Hellström et al $2015^{28}$ & $x$ & & \\
\hline Scharrer et al $2014^{35}$ & & $\mathrm{X}^{\star}$ & \\
\hline Mario et al $2014^{29}$ & $x$ & & \\
\hline Rudolf et al, $2020^{33}$ & $x$ & & \\
\hline Smyth et al $2007^{34}$ & & $x$ & \\
\hline Wallenius et al $2009^{32}$ & $\mathrm{x}$ & & \\
\hline Weaver et al $2009^{30}$ & $x$ & & \\
\hline Zapata et al $2006^{31}$ & $x$ & & \\
\hline
\end{tabular}

*Scharrer et al was designed like a randomised experimental study but there were no baseline assessments of outcomes. Therefore, it was considered a prospective cohort study.

Table 2 Participants and locations

\begin{tabular}{|c|c|c|c|c|c|}
\hline \multirow[b]{2}{*}{ Authors } & \multicolumn{2}{|l|}{ Age } & \multirow[b]{2}{*}{ Boy/girl ratio } & \multirow[b]{2}{*}{ Location } & \multirow[b]{2}{*}{$\mathrm{N}$ total } \\
\hline & $\begin{array}{l}\text { Adolescents } \\
\text { (10-24 years old) }\end{array}$ & $\begin{array}{l}\text { Adults } \\
\text { ( } 25+\text { years old) }\end{array}$ & & & \\
\hline Chaput et al $2011^{36}$ & $15-19$ & & All boys & Denmark & 22 \\
\hline Desai et al $2010^{25}$ & $14-18$ & & $1845 / 2139$ & USA & 3984 \\
\hline DiFrancisco-Donoghue et al $2019^{26}$ & $18-22$ & & N/A & USA \& Canada & 65 \\
\hline Exelmans et al $2015^{27}$ & 18 & 94 & $370 / 474$ & Belgium & 844 \\
\hline Hellström et al $2015^{28}$ & $13-18$ & & $3872 / 3885$ & Sweden & 7757 \\
\hline Scharrer et al $2014^{35}$ & $13-15$ & & $105 / 69$ & Mid-Atlantic states, USA & 176 \\
\hline Mario et al $2014^{29}$ & 18 & 27 & All boys & United Kingdom & 45 \\
\hline Rudolf et al $2020^{33}$ & 20 & 30 & $980 / 86$ & Germany & 1066 \\
\hline Smyth et al $2007^{34}$ & $18-20$ & & $73 / 27$ & New York, USA & 100 \\
\hline Wallenius et al $2009^{32}$ & $12-18$ & & $2500 / 1585$ & Finland & 4085 \\
\hline Weaver et al $2009^{30}$ & 19 & 90 & $271 / 291$ & Seattle, USA & 562 \\
\hline Zapata et al $2006^{31}$ & 14 & & $376 / 415$ & São Paulo, Brazil & 791 \\
\hline
\end{tabular}

expenditure. Table 4 presents the various assessment tools used in each study and the psychometric properties as reported in the original study.

\section{Association between gaming and physical health outcomes}

Sleep and fatigue

Five studies investigated sleep and/or fatigue. ${ }^{27} 29$ 32-34 From these studies, only one ${ }^{34}$ had a high risk of bias but assessment tools and study populations were heterogeneous across studies including sometimes teenagers and young adults and sometimes older adults. One study, ${ }^{27}$ with a low risk of bias, reported a weak association between gaming and lack of sleep or level of fatigue while two low risk of bias studies ${ }^{29}$ found no association between sleep indicators and gaming time. One study did not specifically address the relationship between gaming time and fatigue. ${ }^{32}$ Based on heterogeneity among samples (studies involving either video gamers and eSport athletes) and assessment tools used in these studies, there is insufficient evidence to determine if any association exists between sleep quality, fatigue and video game playing time.

\section{BMI}

Five studies investigated BMI, ${ }^{25} 29303335$ three of them having a low risk of bias. Two low risk of bias studies ${ }^{29} 30$ conducted in teenagers and adult populations found a moderate association between gaming and BMI, one low risk of bias study ${ }^{33}$ found a weak association between gaming and BMI, while one low risk of bias study ${ }^{35}$ found no association in teenagers. Based on these studies and because of the heterogeneity of studied populations, we conclude that there is preliminary evidence that increasing hours of video game playing is associated with increased BMI in adults only. 
Table 3 Risk of bias assessment

\begin{tabular}{|c|c|c|c|c|c|c|}
\hline Authors & Selection & Performance & Detection & Attrition & $\begin{array}{l}\text { Selective } \\
\text { reporting }\end{array}$ & Total \\
\hline Desai et al $2010^{25}$ & High & High & High & Low & Low & High \\
\hline DiFrancisco-Det al. $2019^{26}$ & High & Low & High & High & High & High \\
\hline Exelmans et al $2015^{27}$ & Low & Low & High & Low & Low & Low \\
\hline Hellström et al $2015^{28}$ & High & Low & High & Low & Low & Low \\
\hline Scharrer et al $2014^{35}$ & High & Low & High & Low & Low & Low \\
\hline Mario et al, $2014^{29}$ & High & Low & High & Low & Low & Low \\
\hline Rudolf et al $2020^{33}$ & High & Low & High & Low & Low & Low \\
\hline Smyth et al $2007^{34}$ & High & Low & High & Low & High & High \\
\hline Wallenius et al $2009^{32}$ & High & Low & High & Low & Low & Low \\
\hline Weaver et al $2009^{30}$ & Low & Low & High & Low & Low & Low \\
\hline Zapata et al 2006 31 & Low & Low & High & Low & Low & Low \\
\hline Authors & $\begin{array}{l}\text { Randomization } \\
\text { process }\end{array}$ & $\begin{array}{l}\text { Effect of } \\
\text { assignment to } \\
\text { intervention }\end{array}$ & $\begin{array}{l}\text { Missing } \\
\text { outcome } \\
\text { data }\end{array}$ & $\begin{array}{l}\text { Measurement of } \\
\text { the outcome }\end{array}$ & $\begin{array}{l}\text { Selection of the } \\
\text { reported result }\end{array}$ & Total \\
\hline Chaput et al $2011^{36}$ & Low & Some concerns & Low & Low & Low & Low \\
\hline
\end{tabular}

Table 4 Outcomes assessment tools psychometric value

\begin{tabular}{|c|c|c|c|}
\hline Variable & Study & Measurement tools & $\begin{array}{l}\text { Psychometrics (obtained directly from original studies } \\
\text { or from references included in the original studies) }\end{array}$ \\
\hline Fatigue & 9 & Homemade questionnaire & $\begin{array}{l}\text { Reliability: } 0.58-0.79 \text { (Pearson product moment } \\
\text { correlations) } \\
\text { Validity: N/A } \\
\text { Responsiveness: N/A } \\
\text { MCID: N/A } \\
\text { Other: N/A }\end{array}$ \\
\hline \multirow[t]{2}{*}{ Sleep quality } & 4,7 & $\begin{array}{l}\text { Pittsburgh Sleep Quality Index } \\
\text { (PSQI) }\end{array}$ & $\begin{array}{l}\text { Reliability: } 0.85 \text { (Test-retest correlation) \& } 0.83 \text { (Cronbach's } \\
\text { a) } \\
\text { Validity: } 89.6 \% \text { sensitivity } \& 86.5 \% \text { specificity } \\
\text { Responsiveness: N/A } \\
\text { MCID: N/A } \\
\text { Other: N/A }\end{array}$ \\
\hline & 8,12 & Homemade questionnaire & $\begin{array}{l}\text { Reliability: N/A } \\
\text { Validity: N/A } \\
\text { Responsiveness: N/A } \\
\text { MCID: N/A } \\
\text { Other: N/A }\end{array}$ \\
\hline BMI & $2,6,71012$ & $\begin{array}{l}\text { Homemade questionnaire } \\
\text { asking for weight and height }\end{array}$ & $\begin{array}{l}\text { Reliability: } 0.52-0.92 \text { (Cronbach's } \alpha \text { ) } \\
\text { Validity: N/A } \\
\text { Responsiveness: N/A } \\
\text { MCID: N/A } \\
\text { Other: N/A }\end{array}$ \\
\hline
\end{tabular}


Table 4 Continued

\begin{tabular}{|c|c|c|c|}
\hline Variable & Study & Measurement tools & $\begin{array}{l}\text { Psychometrics (obtained directly from original studies } \\
\text { or from references included in the original studies) }\end{array}$ \\
\hline & 11 & Homemade questionnaire & $\begin{array}{l}\text { Reliability: N/A, but the authors ran a pre-test with } 131 \\
\text { adolescents to assure the consistency and the clarity. } \\
\text { Validity: N/A } \\
\text { Responsiveness: N/A } \\
\text { MCID: N/A } \\
\text { Other: N/A }\end{array}$ \\
\hline \multirow[t]{3}{*}{ Dietary behaviours } & 1 & Ad libitum test meal & $\begin{array}{l}\text { Reliability: } \mathrm{R}^{2}=0.742, \mathrm{p}<0.0001 \text { ( } 2 \text {-day test-retest } \\
\text { correlation) } \\
\text { Validity: N/A } \\
\text { Responsiveness: N/A } \\
\text { MCID: N/A } \\
\text { Other: N/A }\end{array}$ \\
\hline & 1 & Indirect calorimetry & $\begin{array}{l}\text { Reliability: N/A } \\
\text { Validity: } 1.5 \% \text { variability (weekly validation with the alcohol } \\
\text { burning test) } \\
\text { Responsiveness: N/A } \\
\text { MCID: N/A } \\
\text { Other: N/A }\end{array}$ \\
\hline & 7 & $\begin{array}{l}\text { Food frequency questionnaire } \\
\text { (EPIC-FFQ) }\end{array}$ & $\begin{array}{l}\text { Reliability: } 0.8 \text { (female) and } 0.9 \text { (male) } \\
\text { Reproducibility at } 6 \text { months ranged from } \\
\text { Validity: } 0.77 \text { (male)-0.62(female)Pearson correlation } \\
\text { coefficients with } 24-\text { hour dietary recall. } \\
\text { Responsiveness: N/A } \\
\text { MCID: N/A } \\
\text { Other: N/A }\end{array}$ \\
\hline \multirow[t]{3}{*}{$\begin{array}{l}\text { General health/ } \\
\text { health status }\end{array}$} & 9 & Homemade questionnaire & $\begin{array}{l}\text { Reliability: 0.58-0.79 (Pearson product moment } \\
\text { correlations) } \\
\text { Validity: N/A } \\
\text { Responsiveness: N/A } \\
\text { MCID: N/A } \\
\text { Other: N/A }\end{array}$ \\
\hline & 8,12 & Homemade questionnaire & $\begin{array}{l}\text { Reliability: N/A } \\
\text { Validity: N/A } \\
\text { Responsiveness: N/A } \\
\text { MCID: N/A } \\
\text { Other: N/A }\end{array}$ \\
\hline & 10 & $\begin{array}{l}\text { Behavioural Risk Factor } \\
\text { Surveillance System }\end{array}$ & $\begin{array}{l}\text { Reliability: } 0.7-0.8 \text { (Cronbach's } \alpha \text { ) } \\
\text { Validity: N/A } \\
\text { Responsiveness: N/A } \\
\text { MCID: N/A } \\
\text { Other: N/A }\end{array}$ \\
\hline
\end{tabular}


Table 4 Continued

\begin{tabular}{|c|c|c|c|}
\hline Variable & Study & Measurement tools & $\begin{array}{l}\text { Psychometrics (obtained directly from original studies } \\
\text { or from references included in the original studies) }\end{array}$ \\
\hline $\begin{array}{l}\text { Physical activity } \\
\text { and sedentary } \\
\text { behaviours }\end{array}$ & 7 & $\begin{array}{l}\text { International Physical Activity } \\
\text { Questionnaire (IPAQ, long- } \\
\text { version) }\end{array}$ & $\begin{array}{l}\text { Reliability: } 0.8 \text { (test-retest Spearman correlation } \\
\text { coefficients) } \\
\text { Validity: } 0.33,95 \% \mathrm{CI} 0.26 \text { to } 0.39 \text { (Spearman's coefficients) } \\
\text { Responsiveness: N/A } \\
\text { MCID: N/A } \\
\text { Other: N/A }\end{array}$ \\
\hline & 3,12 & Homemade questionnaire & $\begin{array}{l}\text { Reliability: N/A } \\
\text { Validity: N/A } \\
\text { Responsiveness: N/A } \\
\text { MCID: N/A } \\
\text { Other: N/A }\end{array}$ \\
\hline
\end{tabular}

BMI, body mass index; MCID, minimal clinically important change score; N/A, not available in the study.

\section{General health status}

Four studies reported general health status outcomes 303234 and three of them had a low risk ${ }^{30} 3233$ of bias, while the other one had a high risk of bias. ${ }^{34}$ One low risk of bias study reported a poorer health status in video game players compared with non-players ${ }^{30}$ and one low risk of bias study found a weak negative association between playing time and self-reported health status. ${ }^{33}$ Another study $^{32}$ indicated that ritualised motives to play video games contributed significantly to health complaints in boys and girls. This latter association, although significant was marginal. Based on these studies and because of the heterogeneity of studied populations, we conclude that there is preliminary evidence that increasing hours of video game playing is negatively associated with general health status.

\section{Musculoskeletal pain}

Three studies investigated musculoskeletal pain, ${ }^{26} 2831$ all of them having a low risk of bias. One study ${ }^{26}$ reported only descriptive statistics for various musculoskeletal complaints among eSport athletes. One study ${ }^{28}$ reported a weak association between gaming time and musculoskeletal pain, while another study ${ }^{31}$ concluded that gaming was not associated with back pain, pain in upper limbs or diffuse pain. Given that musculoskeletal pain and complaints were self-reported using nonvalidated tools and based on two contradictory low risk of bias studies we conclude that there is insufficient evidence to determine if any association exists between time spent playing video games and musculoskeletal pain.

\section{Level of physical activity and sedentary behaviours}

Three studies investigated the level of physical activity. ${ }^{26} 2933$ One low risk of bias study ${ }^{29}$ reported a moderate negative association between vigorous physical activities while one low risk of bias study reported no association. ${ }^{33}$ One high risk of bias study ${ }^{26}$ reported only descriptive statistics (40\% of the players do not participate in any kind of physical activity). Based on the two low risk of bias studies, there is conflicting evidence that increasing hours of video game playing is negatively associated with physical activity.

\section{Dietary behaviours}

Three studies, all with low risk of bias, measured dietary behaviours. $^{293336}$ One study ${ }^{29}$ reported no difference in energy intake between frequent and non-frequent players while the other study, ${ }^{36}$ the only experimental study included in the review, showed that video game playing is associated with an increased food intake, regardless of appetite sensations. Another low risk of bias study found no association between video game playing time and fruit and vegetable consumption. ${ }^{33}$ Based on low risk but contradictory and heterogeneous studies, we conclude that there is insufficient evidence to determine if any association exists between time spent playing video games and either energy intake/expenditure or fruit and vegetable consumption.

\section{DISCUSSION}

This scoping review focused on the impacts of video games on physical health indicators and behaviours of healthy video game players. In this study, physical health is defined as a multi-component construct that refers to health complaints and acute health concerns (notably injuries), but also includes lifestyle choices like commitments to physical activity, nutritious diets and sufficient sleep. Based on the current evidence regarding the effect of screen time on physical health indicators, we hypothesised that increased time spent playing video games would be associated with a deterioration in physical health indicators. After analysing the relatively scarce and recent available evidence on the topic, it is now possible to synthetise the main findings regarding the different health outcomes.

Because of their methodological approach and specific research questions, some articles deserve to be discussed individually. Chaput and colleagues ${ }^{36}$ were the only study 
in this scoping review that used a randomised crossover methodology and is also the only study using direct measurement to measure energy balance. Another study published by Hellström and colleagues ${ }^{28}$ investigated the motives to play video games and the association between such motives and various health outcomes. Finally, DiFrancisco and colleagues ${ }^{26}$ adopted a more descriptive approach, but opted to measure a population of eSport athlete, which makes it the only study currently addressing physical health outcomes and E-gaming.

Another review in which massively multiplayer online games were studied ${ }^{37}$ found 'inconclusive evidence' regarding the relationship between regular massively multiplayer online games gameplay and negative consequences to physical or psychosocial health of players, although they found a positive relationship between gaming addiction and worse overall health and sleep quality. The authors also reported that a major limitation of their study was the poor quality of the research in the field of gaming. A systematic review ${ }^{38}$ explored the effect of gaming on physical and psychological health among users for the past 20 years. They found that the impact is variable depending on the type of gamer, but that playing more than 5 hours per week was associated with negative outcomes like musculoskeletal injuries, higher BMI and sleeping problems. The latter review included studies either about general and mental health, aggressive and social behaviours and educational benefits but did not assess specific categories of physical health outcomes and only provided broad results and conclusions on these outcomes. Moreover, the authors did not conduct a risk of bias analysis which limits the interpretation and generalisability of their results.

Several physical health indicators and behaviours were identified in the selected articles. The conflicting evidence suggesting a possible negative association between physical activity levels and time spent playing video games, even if preliminary, seems important since physical activity levels are closely related to long-term health indicators, such as blood pressure, diabetes or BMI. ${ }^{39} 40$ A recent study exploring associations between sitting time, physical activity and BMI concluded that individuals that spend more time seated ( 8 or more hours per day) were more likely to have a higher BMI and lower physical activity participation. ${ }^{41}$ Given that preliminary evidence also suggest that increasing hours of video game playing are associated with increased BMI in adults, more studies investigating the relationship between video games physical activity, obesity and cardiometabolic health outcomes are warranted. The effect of video game playing on physical activity seems to vary according to the type of video gaming. For instance, preliminary results suggest that $73 \%$ of eSports players are able to meet physical activity guideline potentially because of their motivation to stay healthy and enhance their physical capacity. ${ }^{42}$ Alternatively, because they require the participants to move their body to progress, as opposed to classic video games or other screen-based activities, ${ }^{43}$ exergames seem to momentarily increase light-intensity to moderateintensity physical activity. Their effect on long-term commitment to physical activity or decreases in sedentary behaviour, however, is less clear. ${ }^{44}$ The results and conclusion of this review may have differed if active or exergames would have been included.

One of the major concerns of public health stakeholders is the impact of screen time on population health. When compared with the overall body of evidence related to screen time and physical health, this scoping review suggests that the relative consequences are generally similar to those observed when individuals spend time in front of a screen, regardless of whether they play video games, watch television or interact on social media. A recent review by Hale and Guan investigating screen time and sleep hypothesised that sleep was negatively impacted by screen time. ${ }^{13}$ They found that, in $90 \%$ of the reviewed studies, sleep was negatively impacted by time spent gaming. Moreover, the physiological and psychological states of arousal caused by the content of the media or resulting social interactions can negatively impact the ability to fall or stay asleep. Finally, the authors reported that prolonged screen light exposure before bed (more than 2 hours) is suggested to alter the circadian rhythm through the suppression of melatonin and affect the quality of sleep. Moreover, a recent study highlighted an inverse association between time spent in front of a screen and moderate to vigorous physical activity. ${ }^{45}$

One of the key strengths of this review is the fact that it strictly focuses on video games and no other type of screen-related activities. This distinction can be useful for public health stakeholders to develop and disseminate recommendations to the public; it can also help scientists to identify strengths and weaknesses in the literature. Another relevant contribution of this review is that it isolates the physical component of health and ignore psychosocial outcomes. There is much more evidence regarding the latter outcomes, while physical outcomes such as sleep, physical activity and energy balance are often relegated to a secondary role. Limitations of this review include the sometimes small sample and heterogeneity of the included studies. Indeed, the available evidence regarding the relationship between physical health and time spent playing video games is still limited and most of the studies were published in the last $10-15$ years. Also, given the composition of the research team, it was decided that only studies written in French or English would be included for analysis. The impact of such language exclusion is that the number of potentially excluded but relevant publications is unknown. Finally, because original studies included in this scoping review were mostly cross-sectional studies, the temporal relationship between exposure and outcomes as well as other criteria for causation cannot be determined.

Given the aforementioned limitations, future research should include experimental research design using 
control groups to better understand the mechanisms underpinning the relationship between video games and the deterioration of physical health outcomes. Considering the associations between gaming and physical health indicators, public health stakeholders should continue to encourage the population, especially children and adolescents, to adopt an active lifestyle and promote physical activity. Furthermore, researcher should continue to explore such associations and assess video gaming and health indicators with precise and validated measurement tools. Another possible solution would be to better monitor and organise the practice of video games. Playing within the framework of organised extracurricular activities where children and adolescents could practice video games under the supervision of a trained adult is certainly a promising approach to gaming. A recent study ${ }^{46}$ highlighted the potential of eSports as a means of improving life skills such as commitment, cooperation and communication among young athletes as well as a potential catalyst to improve lifestyle habits and physical activity practice, especially among the young people.

\section{CONCLUSION}

This scoping review overviews the few studies exploring the topic of video gaming and physical health. Results suggest preliminary evidence of an association between video game playing time and a deterioration of some physical health indicators and behaviours such as BMI and general health status. Overall, available evidence is scarce and was mostly published recently. More studies are needed to increase our understanding of video gaming effects on physical health and related health behaviours.

Contributors MD and CT designed the study and the search strategy whereas the selection process, extraction and risk of bias analyses were carried out by VHP, AL and FP. VHP and AL wrote the manuscript, while MD and CT directed the project and reviewed all stages of the study including writing the manuscript.

Funding The study was funded by the Chaire de recherche internationale en santé neuromusculosquelettique.

Competing interests None declared.

Provenance and peer review Not commissioned; externally peer reviewed.

Supplemental material This content has been supplied by the author(s). It has not been vetted by BMJ Publishing Group Limited (BMJ) and may not have been peer-reviewed. Any opinions or recommendations discussed are solely those of the author(s) and are not endorsed by BMJ. BMJ disclaims all liability and responsibility arising from any reliance placed on the content. Where the content includes any translated material, BMJ does not warrant the accuracy and reliability of the translations (including but not limited to local regulations, clinical guidelines, terminology, drug names and drug dosages), and is not responsible for any error and/or omissions arising from translation and adaptation or otherwise.

Open access This is an open access article distributed in accordance with the Creative Commons Attribution Non Commercial (CC BY-NC 4.0) license, which permits others to distribute, remix, adapt, build upon this work non-commercially, and license their derivative works on different terms, provided the original work is properly cited, appropriate credit is given, any changes made indicated, and the use is non-commercial. See: http://creativecommons.org/licenses/by-nc/4.0/.

ORCID iD

Martin Descarreaux http://orcid.org/0000-0002-3545-5860

\section{REFERENCES}

1 ESA. Essential facts about the computer and video game industry 2019. April 2020. Available https://www.theesa.com/wp-content /uploads/2019/05/2019-Essential-Facts-About-the-Computer-andVideo-Game-Industry.pdf

2 Freeman G, Wohn DY eSports as an emerging research context at $\mathrm{CHI}$ : diverse perspectives on definitions. Proceedings of the $2017 \mathrm{CHI}$ Conference Extended Abstracts on Human Factors in Computing Systems. Denver, CO, USA: Association for Computing Machinery, 2017: 1601-8.

3 Martin G. IOC president bach writes to olympic movement: Olympism and corona. Available https://www.olympic.org/news/ioc-presidentbach-writes-to-olympic-movement-olympism-and-corona2020

4 AACRAO. Video gaming: the newest college sport. Officers TAAOCRAA. 2018. Available https://www.aacrao.org/resources/news letters-blogs/aacrao-connect/article/video-gaming-the-newestcollege-sport

5 Mentzoni RA, Brunborg GS, Molde H, et al. Problematic video game use: estimated prevalence and associations with mental and physical health. Cyberpsychol Behav Soc Netw 2011;14:591-6.

6 Ferguson CJ. The school shooting/violent video game link: causal relationship or moral panic? J Investigative Psychol Offender Profiling 2008;5:25-37.

7 Choo H, Gentile D, Sim T, et al. Pathological video-gaming among Singaporean youth. 2010.

8 Black DW, Grant JE. DSM-5 guidebook: the essential companion to the diagnostic and statistical manual of mental disorders. 5th edn. 1 online resource $\mathrm{p}$.

9 Pontes HM, Griffiths MD. Internet addiction disorder and internet gaming disorder are not the same. J Addict Res Ther 2014;5:4.

10 Boone JE, Gordon-Larsen P, Adair LS, et al. Screen time and physica activity during adolescence: longitudinal effects on obesity in young adulthood. Int J Behav Nutr Phys Activity 2007;4:26.

11 Ahluwalia N, Frenk SM, Quan SF. Screen time behaviours and caffeine intake in US children: findings from the cross-sectional National Health and Nutrition Examination Survey (NHANES). BMJ Paediatrics Open 2018;2:1.

12 Pan J-Y, Choi M-J. The effects of nutrient intake and screen time (television viewing and computer and/or video games) on preschool children obesity. J East Asian Soc of Dietary Life 2011;21:185-93.

13 Hale L, Guan S. Screen time and sleep among school-aged children and adolescents: a systematic literature review. Sleep Med Rev 2015;21:50-8.

14 Elliott L, Ream G, McGinsky E, et al. The contribution of game genre and other use patterns to problem video game play among adult video gamers. Int J Ment Health Addict 2012;10:948-69.

15 Kremer P, Elshaug C, Leslie E, et al. Physical activity, leisure-time screen use and depression among children and young adolescents. J Sci Medicine Sport 2014;17:183-7.

16 Kallio KP, Mäyrä F, Kaipainen K. At least nine ways to play: approaching gamer mentalities. Games Culture 2011;6:327-53.

17 Prot S, McDonald KA, Anderson CA, et al. Video games: good, bad, or other? Pediatric Clinics 2012;59:647-58.

18 Arksey H, O'Malley L. Scoping studies: towards a methodological framework. Int J Soc Res Methodol 2005;8:19-32.

19 Ames ME, Leadbeater BJ, Merrin GJ, et al. Patterns of marijuana use and physical health indicators among Canadian youth. Int $J$ Psychol 2020;55:1-12.

20 Schardt C, Adams MB, Owens T, et al. Utilization of the PICO framework to improve searching PubMed for clinical questions. BMC Med Inform Decis Mak 2007;7:16.

21 Guyatt GH, Oxman AD, Schünemann HJ, et al. GRADE guidelines: a new series of articles in the Journal of Clinical Epidemiology. $J$ Clin Epidemiol 2011;64:380-2.

22 Sterne JA, Savović J, Page MJ, et al. RoB 2: a revised tool for assessing risk of bias in randomised trials. BMJ 2019;366.

23 Balshem H, Helfand M, Schünemann HJ, et al. Grade guidelines: 3. Rating the quality of evidence. J Clin Epidemiol 2011;64:401-6.

24 O'Neil M, Berkman N, Hartling L, et al. Observational evidence and strength of evidence domains: case examples. Syst Rev 2014;3:35.

25 Desai RA, Krishnan-Sarin S, Cavallo D, et al. Video-gaming among high school students: health correlates, gender differences, and problematic gaming. Pediatrics 2010;126:e1414-e24.

26 DiFrancisco-Donoghue J, Balentine J, Schmidt G, et al. Managing the health of the eSport athlete: an integrated health management model. BMJ Open Sport Exerc Med 2019;5:e000467.

27 Exelmans L, Van den Bulck J. Sleep quality is negatively related to video gaming volume in adults. J Sleep Res 2015;24:189-96.

28 Hellström C, Nilsson KW, Leppert J, et al. Effects of adolescent online gaming time and motives on depressive, musculoskeletal, and psychosomatic symptoms. Ups J Med Sci 2015;120:263-75. 
29 Mario S, Hannah C, Jonathan WC, et al. Frequent video-game playing in young males is associated with central adiposity and high-sugar, low-fibre dietary consumption. Eat Weight Disord 2014;19:515-20.

30 Weaver III JB, Mays D, Weaver SS, et al. Health-risk correlates of video-game playing among adults. Am J Prev Med 2009;37:299-305.

31 Zapata AL, Moraes AJP, Leone C, et al. Pain and musculoskeletal pain syndromes related to computer and video game use in adolescents. Eur J Pediatr 2006;165:408-14.

32 Wallenius M, Rimpelä A, Punamäki R-L, et al. Digital game playing motives among adolescents: relations to parent: child communication, school performance, sleeping habits, and perceived health. J Appl Dev Psychol 2009;30:463-74.

33 Rudolf K, Bickmann P, Froböse I, et al. Demographics and health behavior of video game and eSports players in germany: the esports study 2019. Int J Environ Res Public Health 2020;17:1870.

34 Smyth JM. Beyond self-selection in video game play: an experimental examination of the consequences of massively multiplayer online role-playing game play. CyberPsychology Behavior 2007;10:717-21.

35 Scharrer E, Zeller A. Active and sedentary video game time. J Media Psychol 2014;26:39-49.

36 Chaput J-P, Visby T, Nyby S, et al. Video game playing increases food intake in adolescents: a randomized crossover study. Am J Clin Nutr 2011;93:1196-203.
37 Sublette VA, Mullan B. Consequences of play: a systematic review of the effects of online gaming. Int $J$ Ment Health Addict 2012;10:3-23.

38 John N, Sharma MK, Kapanee ARM. Gaming - a bane or a boon-a systematic review. Asian J Psychiatr 2019:42:12-17.

39 Brach JS, Simonsick EM, Kritchevsky S, et al. The association between physical function and lifestyle activity and exercise in the health, aging and body composition study. J Am Geriatr Soc 2004;52:502-9.

40 Hallal PC, Victora CG, Azevedo MR, et al. Adolescent physical activity and health. Sports Med 2006;36:1019-30.

41 Bullock VE, Griffiths P, Sherar LB, et al. Sitting time and obesity in a sample of adults from Europe and the USA. Ann Hum Biol 2017;44:230-6.

42 Pereira AM, Figueiredo P, Seabra A, et al. Evaluation of physical activity levels in FPF eSports e-athletes. Motricidade 2019;15:188.

43 Mears D, Hansen L. Active gaming: definitions, options and implementation. Article\# 5 in a 6-part series. Strategies. 2009;23:26-9.

44 LeBlanc AG, Chaput J-P, McFarlane A, et al. Active video games and health indicators in children and youth: a systematic review. PloS One 2013;8:e65351.

45 Dalene KE, Anderssen SA, Andersen LB, et al. Cross-sectional and prospective associations between sleep, screen time, active school travel, sports/exercise participation and physical activity in children and adolescents. BMC Public Health 2018;18:705.

46 Carbonie A, Guo Z, Cahalane M, eds. Positive personal development through eSports. PACIS, 2018. 